\title{
Effect of Fenugreek Seed and Leaves on Some Hematological and Biochemical Parameters in CCl4-induced Liver Injury
}

\author{
Firdaws A. AL-Mashhadani* \\ Food technology Dep., Agriculture College, Salahaddin University, Erbil, Iraq \\ *Corresponding author
}

\author{
A B S T R A C T
}

\begin{tabular}{|l|}
\hline Ke y w o r d s \\
Fenugreek, \\
CCL4 - \\
Induced \\
liver injury. \\
\hline Article Info \\
\hline $\begin{array}{l}\text { Accepted: } \\
\text { 20 March } 2017 \\
\text { Available Online: } \\
\text { 10 April } 2017\end{array}$ \\
\hline
\end{tabular}

This study was carried out to evaluate the effect of fenugreek plant on CCL4 -induced liver injury by following the hematological and biochemical parameters. To achieve this purpose forty male albino rats were used and divided to four groups. The first group represented control group which received normal diet and intraperitoneal injection with oil $(0.5 \mathrm{ml} / \mathrm{kg})$. The second group represented the CCL $(1 \mathrm{ml} / \mathrm{kg})$ model. The third group received $200 \mathrm{mg} / \mathrm{kg}$ fenugreek leaves extract by gavage. The forth group received 500 $\mathrm{mg} / \mathrm{kg}$ fenugreek seed extract by gavage. The fenugreek seed and leave extracts treated group showed significant differences in AST, ALT, ALP, direct bilirubin, MDA, GSH, liver SOD, WBC, LYM and PLT when compared to $\mathrm{CCl}_{4}$ treated rats. These results indicate that these plants can be used as a good source of antioxidant and hepatic protective activities as well as a good antibiotic agent against some pathogenic bacteria. The methanolic extract of fenugreek seeds with different concentrations in ml inhibited the growth of the pathogenic E. coli, Staphylococcus aureus and Bacillus subtilis bacteria more than the aqueous extract for the fenugreek leaves and seeds.

\section{Introduction}

Medicinal plants are important part of health care. Large varieties of plants (more than 1200) are available with known therapeutic effects (Kipkore et al., 2014). Approximately $70-80 \%$ people worldwide depend on medicinal plants to cure various human ailments including viral diseases (Wang and Liu, 2013). Moreover, herbal drugs have gained much importance due to their easily adaptability, low cost and fewer side reactions on patients (Edziri et al., 2011).

Natural antioxidants can protect the body against the adverse effects of $\mathrm{CCl} 4$ and some other toxins (Kader et al., 2014, Amini et al., 2012). Medicinal plants have been used to treat various disorders throughout the history of human life, but the use of synthetic drugs was highly prevalent since the middle of last century (Sewell and Rafieian-Kopaei, 2014). With the rapid detection of their adverse side effects of synthetic drugs on public health, the trend is increasing for application of medicinal plants as alternatives to synthetic ones (Bahmani et al., 2014a,b).

Fenugreek (Trigonella foenum graecum Linn) is an annual herb that belongs to the family Leguminosae. The seeds of fenugreek are commonly used in the Middle East and South Asia as a spice in food preparation and used as traditional medicines in diabetes, high 
cholesterol, inflammations and gastrointestinal ailments (Basu et al., 2010; Belguith-Hadriche et al., 2010).

Liver diseases are one of the major causes of mortality and morbidity worldwide, druginduced liver toxicity is a major cause of hepatic dysfunction (Abboud and Kaplowitz, 2007). Oxidative stress is considered as a mechanism in contributing to the initiation and progression of hepatic damage in a variety of liver disorders. Cell damage occurs when there is an excess of reactive species derived from oxygen and nitrogen or deficiency of antioxidants (Girish and Pradhan, 2008a). Oxidative stress, involving enhanced generation of reactive oxygen species (ROS), has been implicated in the etiology of many human diseases. Antioxidants capable of neutralizing ROS and their actions are considered beneficial. In this context, natural dietary components with antioxidant activities could be important (Bandyopadhyay et al., 1999; Yamamoto, 2000).

Among environmental toxins, carbon tetrachloride (CCl4) dedicated most of conducted studies to itself (Olagunju et al., 2009).

Fenugreek has a good antimicrobial property because. It contains certain bioactive components such as volatile oils, alkaloids, mucilage. All these components in Fenugreek adds on to its antibacterial activity. They contain multiple constituents with antimicrobial activity including phenols, quinones, flavones, tannins, terpenoids, and alkaloids (24).

Aim of this study was to study the antioxidant activity of fenugreek plant and its hepatic protective activity and to determine the oxidative stress and antioxidant markers and some hematological parameters in CCL4 treated rat groups. Also the aim of this study is to evaluate the effect of ethanolic and aqueous extracts of the seeds and leaves of fenugreek against various pathogenic bacteria growth.

\section{Materials and Methods}

\section{Materials}

\section{Plant preparation}

A Fenugreek (Trigonella foenum graecum) seeds and leaves sample were collected from the local market of Baghdad. Dry fenugreek seed and leaves were cleaned and ground into small pieces by a blender and $70 \%$ ethanol was used extraction by soxhelt extraction method for six hours.

The extracts were combined, and evaporated to dryness under reduced pressure at $60 \mathrm{Co}$ by a rotary evaporator. Extracts were placed in dark bottle, and stored at $-4 \mathrm{C}^{\circ}$ until further analysis. The extract was suspended in distilled water for hepato protective studies (Bukhari et al., 2008).

\section{Experimental animals}

Forty male albino rats (Rattus norvegicus), weighing about 250 - 350gm were used.

The animals were given standard rat diet chow and housed in plastic cages bedded with wooden chips in a room with controlled temperature of $24 \pm 3^{\circ} \mathrm{C}, 12 / 12$ hours light/dark schedule in an animal house belong to Biology department, College of Science, Salahaddin University-Erbil.

Standard chaw ingredients included (wheat $66.6 \%$,soya $25.6 \%$, oil sun flower $4.4 \%$, lime stone $1.5 \%$, salt $0.63 \%$, methionine $0.158 \%$, Lysine $0.24 \%$, choline chloride $0.062 \%$ and trace elements $0.05 \%$ ) 


\section{Experimental Design}

The experimental rats were divided randomly to 4 groups. This experiment was carried out for four weeks as explained below:

Group 1: Control rats $(\mathrm{n}=10)$

The rats of this group were given olive oil intraperitoneally $(0.5 \mathrm{ml} / \mathrm{kg}$ body weight $)$ for four weeks.

Group 2: CCl4 treated rats $(\mathrm{n}=10)$

The rats of this group were given $\mathrm{CCl} 4$ intraperitoneally $1 \mathrm{ml} / \mathrm{kg}$ b.w. (1:1 in olive oil) for four weeks

Group 3: Fenugreek $(\mathrm{n}=10)$

The rats of this group were given $\mathrm{CCl} 4$ intraperitoneally $1 \mathrm{ml} / \mathrm{kg}$ b.w. (1:1 in olive oil) and fenugreek seeds extract $500 \mathrm{mg} / \mathrm{kg}$ dissolved in distilled water and given to rats by gavage daily for four weeks.

\section{Group 4: Fenugreek leaves $(\mathrm{n}=10)$}

The rats of this group were given $\mathrm{CCl} 4$ intraperitoneally $1 \mathrm{ml} / \mathrm{kg}$ b.w. (1:1 in olive oil) and Fenugreek leaves extract $200 \mathrm{mg} / \mathrm{kg}$ dissolved in water and given to rats by gavage daily for four weeks

\section{Methods}

\section{Tissue preparation}

Anesthesia, dissecting, liver and kidney removing

All animals were anesthetized with Ketamine hydrochloride $80 \mathrm{mg} / \mathrm{Kg}$ (Trittau, Germany) and Xylazin $12 \mathrm{mg} / \mathrm{Kg}$ (Interchem, Holland). The liver was removed then divided into two equal parts, one part cut into small pieces (less than $0.5 \mathrm{~cm} 3$ thicknesses) then kept in formalin, while the other part stored at refrigerators until homogenized for estimation of SOD, HYP and GSH.

\section{Tissue homogenate}

Liver washed with cold saline. Pieces of each tissue used for homogenization by $20 \mathrm{mM}$ cold phosphate buffer saline $(\mathrm{pH}$ 7.4). The liver tissues homogenized $(10 \% \mathrm{w} / \mathrm{v})$ using handheld glass homogenizer (Chowdhury et al., 2013). Homogenates were centrifuged at $6000 \mathrm{rpm}$ for 10 minutes. The supernatants were collected and stored at -80Co until assayed.

\section{Estimation of glutathione in liver tissue}

The procedure of (Moron et al., 1979) was followed with some modification. Weighting $1 \mathrm{gm}$ of liver tissue and homogenate by using handled homogenizer with $10 \mathrm{ml}$ of cold tris buffer solution. One $\mathrm{ml}$ of tissue homogenate was added to $0.25 \mathrm{ml}$ of $25 \%$ trichloroacetic acid. After centrifugation for 5 minutes at $3000 \mathrm{rpm} 0.2 \mathrm{ml}$ of supernatant was taken in a test tube, adding one $\mathrm{ml}$ o.15mole imidazole solution then adding $1.7 \mathrm{ml}$ distilled water and o.1 $\mathrm{ml}$ 5.5(DTNB) solution finally absorbance was read at $412 \mathrm{~nm}$ after 3 minutes of adding DTNB.

The concentration of GSH was calculated according to the absorbance of blank (B), test (T) and standard (S) solutions by the following equation:

GSH conc. $(\mu \mathrm{mol} / \mathrm{mg}$ of tissue $)=*$ conc. Standard * 100 (3.1)

\section{Determination of liver tissue superoxide dismutase}

Liver samples were washed with $0.9 \% \mathrm{NaCl}$ to remove red blood cells. The tissue was then 
blotted dry and weighed followed by homogenization in $200 \mu \mathrm{l}$ buffer $(0.05 \mathrm{M}$ potassium phosphate and $0.1 \mathrm{mM}$ EDTA, $\mathrm{pH}$ 7.8 ) and centrifuged at $15,000 \mathrm{xg}$ for $30 \mathrm{~min}$ at $4^{\circ} \mathrm{C}$. The supernatant was used for determination of SOD. Superoxide dismutase was measured using the Superoxide Dismutase assay kit provided by Elabscience (Elabscience, WuHan P.R.C).

The concentration of SOD was determined by competitive-ELISA method.

The concentration of SOD in the samples is then determined by comparing the OD of the samples to the standard curve (Figure 1).

\section{Blood collection}

At the end of the treatment period, blood samples were collected from anesthetized rats through cardiac puncture. The collected blood samples were immediately placed into test tube and centrifuged and the sera were stored at -80Co (Sanyo - Ultra - Low Temperature, Japan) until assayed. While, for hematological analysis blood were collected in EDTA tube.

\section{Hematological analysis}

White blood cell (WBC) count, LYM and PLT count were determined automatically by using automated hematology analyzer (Sysmex model: K-1000, Japan).

\section{Determination of Liver Function Paramet}

Alkaline Phosphatase, Aspartate Aminotransferase, Alanine Aminotransferase and bilirubin were achieved automatically by using full automated (COBAS Integra 400plus-roche, Germany).

\section{Statistical analysis}

One way analysis of variance followed by Newman-Keuls post hoc test comparison procedures were used to compare between means of different groups. Data are represented as the mean \pm standard error $(\mathrm{M} \pm \mathrm{SE})$. Graphpad prism program, version 6.01, computer program was used for statistical analysis. $\mathrm{P}<0.05$ was considered statistically significant. Citations and references were managed by Endnote $\mathrm{X} 7$ (Endnote software, Thomson Reutter, Canada)

\section{The Antibacterial Effects of Leave and Seed Watery and Alcoholic Extracts:-}

The inhibitory of many concentrations of leave and seeds was carried out to determine the lowest concentration needed to inhibit visible bacterial growth by fixed concentration of experimental isolates of bacteria after an overnight incubation. The inhibition value of was confirmed based on the inhibition and growth observed on the agar plate which had been carried out as follow:

Leave and seeds in different weights $(0.01$, $0.02,0.1,0.2$ and 0.5$) \mathrm{gm}$ were added to freshly prepared growth media in $250 \mathrm{ml}$ Erlenmeyer flasks containing $100 \mathrm{ml}$ sterile Nutrient agar, these media poured in sterilized petri dish and inoculated with $1 \mathrm{ml}$ of suitable dilution incubated at $37 \mathrm{C}$ for $24 \mathrm{hr}$. The test was carried out in triplicate and the mean value was calculated (AL-Bayaty et al., 2011).

Antibacterial Activity of Leave and Seed Watery and Alcoholic Extracts by Well Diffusion Agar Leave and seeds $0.01 \mathrm{~g}, 0.02$ $\mathrm{g}$, was analyzed for inhibition activities against tested bacteria by agar -well diffusion Muller-Hinton agar seeded with bacterial isolates. The inoculums were prepared by adding (5) isolated colonies grown on Nutrient agar plate to (5) $\mathrm{ml}$ of nutrient broth and incubated at $37 \mathrm{C}^{0}$ for $18 \mathrm{hrs}$. and compared with (0.5) Mcfarland tube. A sterile 
swabs was used to obtain an inoculums was streaked on Muller-Hinton agar plate and left to dry. Wells (5) $\mathrm{mm}$ were hollowed out in agar using a sterile cork borer, a volume of (50) $\mu \mathrm{l}$ of tested extracts compounds were dropped separately in each well, and incubated at $37{ }^{\circ} \mathrm{C}$ for 24 hrs.; inhibition zone around the wells were measured and recorded in millimeter after subtraction $5 \mathrm{~mm}$ (well diameter).

\section{Results and Discussion}

Effect of fenugreek leaves and seed on liver function tests in carbon tetrachloride treated rats

Table (1) shows the effects of fenugreek leaves and seeds on the liver function tests in $\mathrm{CCl} 4$ treated rats. The results of this study showed variations in the level of liver function tests in $\mathrm{CCl} 4$ treated rats. The ALP level was significantly decreased in control $(\mathrm{P}<0.05)$ and fenugreek group $(\mathrm{P}<0.01)$, modified Harvard style but there were no statistical difference of ALP level in fenugreek leave group when compared to the CCl4 treated rats,. Also, AST levels were significantly decreased $(\mathrm{P}<0.001)$ in control, both of fenugreek groups when compared to the $\mathrm{CCl} 4$ treated rats.

Moreover, it revealed that in all treated groups, serum ALT levels were decreased significantly $(\mathrm{P} \leq 0.001)$ compared with $\mathrm{CCl} 4$ treated rats. With respect to direct bilirubin level, control, also both of fenugreek treated groups were significantly decreased $(\mathrm{P} \leq$ 0.001) compared to $\mathrm{CCl} 4$ treated rats.

Results of the current data showed the increase in ALP, AST, ALT and bilirubin levels in $\mathrm{CCl} 4$ treated groups are in agreement with (Girish and Pradhan, 2012). The mechanism of hepatic damage by $\mathrm{CCl} 4$ is well documented by Buege and Aust (1978) they were reported that $\mathrm{CCl} 4$ is metabolized by Cytochrome P450 enzyme to (CCl3). This in turn reacts with molecular oxygen and gets converted to trichloromethyl peroxy radical. This radical forms covalent bonds with sulfhydryl groups of several membrane molecules like GSH leading to their depletion and causes lipid peroxidation. The lipid peroxidation initiates a cascade of reactions leading to liver necrosis. Liver damage is detected by measuring the activities of liver function marker enzymes like AST, ALT and ALP, which are released into the blood from damaged cells. They are also indicators of liver damage (Meera et al., 2009).

Our results showed that extract of fenugreek can prevent the $\mathrm{CCl} 4$ induced toxicity in the liver by significantly reduction of AST, ALT, ALP and direct bilirubin levels, these results are in agreement with (Meera et al., 2009) they achieved that the normalization of the above enzyme levels in rat liver with the plant drugs estabilishes the hepato protective effect of $T$. foenum-graecum which may be able to induce accelerated regeneration of liver cells reducing the leakage of these enzymes into the blood. The results indicated that fenugreek significantly prevented the increased liver function marker enzyme activity induced by $\mathrm{CCl} 4$, indicating an improvement of the functional status of the liver by the fenugreek.

\section{Effect of Fenugreek seed and leave extracts on the some hematological parameters in carbon tetrachloride treated rats}

The results showed (Table 2) that WBC count significantly decreased in fenugreek seeds $(\mathrm{P} \leq$ $0.001)$, but there were no statistical differences in control, fenugreek leaves when compared with $\mathrm{CCl} 4$ treated rats. Moreover, number of LYM significantly decreased in fenugreek seeds $(\mathrm{P} \leq 0.05)$, while there were no significant differences in control, fenugreek leaves when compared with $\mathrm{CCl} 4$ 
treated group. Furthermore, the PLT count significantly decreased in control, fenugreek $(\mathrm{P} \leq 0.01)$, and, fenugreek leaves $(\mathrm{P} \leq 0.05)$ when compared with $\mathrm{CCl} 4$ treated rats.

The present study showed that the rats treated with fenugreek significantly decreased WBC, LYM and PLT when compared with $\mathrm{CCl} 4$ treated rats.

Effect of fenugreek seed and leave extracts on the liver super oxide dismutase and liver glutathione levels in carbon tetrachloride treated rats

As shown in table (3), the level of liver GSH in fenugreek groups significantly increased $(\mathrm{P} \leq 0.001)$, but there was no statistical difference of liver GSH level in control when compared to $\mathrm{CCl} 4$ treated group. Also, liver SOD significantly increased in control $(\mathrm{P} \leq$ $0.001)$, fenugreek seeds and leaves $(\mathrm{P} \leq 0.05)$

Glutathion (GSH) is the most important of the sulfur-containing non-enzymatic antioxidant molecules. GSH can also conjugate with free radicals directly, earmarking them for renal excretion, which is especially important for dealing with the products of hepatic cytochrome P450 enzyme activity. The sulfhydryl $(-\mathrm{SH})$ portion of the GSH can be used to reduce a variety of free radicals in a reaction catalyzed by the antioxidant enzyme, glutathione peroxidase (Webb and Twedt, 2008).

In this study, the GSH level was significantly increased in fenugreek treatment. This is in agreement with (Sushma and Devasena, 2010), they showed that administration of fenugreek seed extract minimized the effects of ethanol in tissues. The beneficial effects of fenugreek seeds are well demonstrated by their ability to improve antioxidant status thereby lowering lipid peroxidation. In vitro investigations revealed that the aqueous extract of fenugreek seeds effectively inhibited the production of TBARS in the presence of promoters of lipid peroxidation. In this manner, the effect of fenugreek aqueous extract was comparable with $\alpha$ tocopherol (Thirunavukkarasu et al., 2003).

Table.1 Effect of fenugreek seed and leaves treatments on liver function test in CCI4-liver injury rats

$\begin{array}{lllll}\text { Groups } & \text { S. ALP (U/L) } & \text { S. AST(U/L) } & \text { S. ALT(U/L) } & \text { S.D. Bilirubin (mg/dL) } \\ & & & & \\ \text { CCl4 } & 326 \pm 25.59 & 812.3 \pm 91.03 & 763.8 \pm 98.49 & 0.09625 \pm 0.006 \\ \text { Control } & 243.4 \pm 27 & 196.4 \pm 35.68 & 53.4 \pm 6.47 & 0.026 \pm 0.002 \\ \text { Fenugreek leave extract } & 280.4 \pm 10.41 & 131.3 \pm 15.31 & 45.33 \pm 1.55 & 0.02733 \pm 0.004 \\ \text { Fenugreek seed extract } & 230 \pm 17.45 & 146.4 \pm 19.84 & 41.88 \pm 2.6 & 0.0295 \pm 0.005\end{array}$

Table.2 Effect of fenugreek seed and leave extracts on the some hematological parametersinCCI4-in liver in jury rats

$\begin{array}{llll}\text { Groups } & \text { WBC } * 103 / \mu \mathrm{L} & \mathrm{LYM} * 103 / \mu \mathrm{L} & \mathrm{PLT}^{*} 103 / \mu \mathrm{L} \\ \text { CC14 } & 9.623 \pm 0.34 & 6.033 \pm 0.12 & 915.4 \pm 16.91 \\ \text { Control } & 8.3 \pm 0.7 & 4.65 \pm 0.15 & 522 \pm 117.5 \\ \text { Fenugreek leaves } & 7.2 \pm 0.55 & 4.533 \pm 0.27 & 582.8 \pm 47.78 \\ \text { Fenugreek seeds } & 4.75 \pm 0.95 & 3.75 \pm 0.55 & 536.6 \pm 122.1\end{array}$


Table.3 Effect of fenugreek seed and leave extracts on GSH and SOD in CCI4- liver injury rats

$\begin{array}{lcl}\text { Groups } & \text { GSH }(\mu \mathrm{mol}) & \text { SOD } \\ \text { CCl4 } & 13.33 \pm 0.7 & 0.03576 \pm 0.0112 \\ \text { Control } & 25.19 \pm 1.33 & 0.2804 \pm 0.03531 \\ \text { Fenugreek leaves } & 108.2 \pm 4.33 & 0.2358 \pm 0.04062 \\ \text { Fenugreek seeds } & 130.2 \pm 8.71 & 0.1802 \pm 0.05225\end{array}$

Fig.1 Standard curve of superoxide dismutase (SOD )

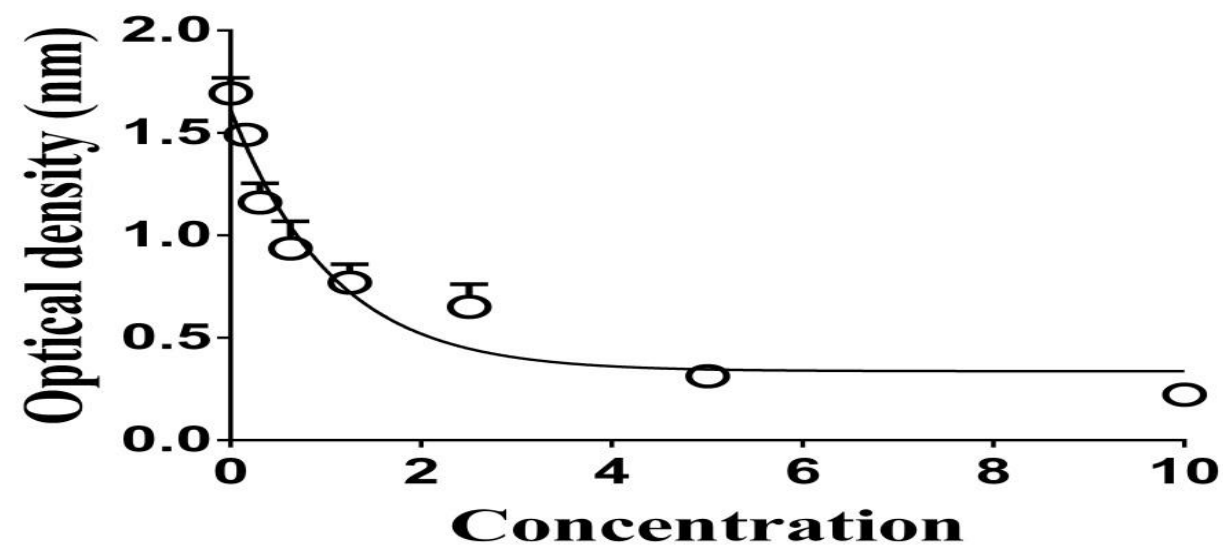

The antibacterial Activity of Fenugreek Leave and Seed watery and alcoholic extracts, inhibition zone measured in millimeter and percentage of inhibition

\begin{tabular}{|l|l|c|c|c|c|}
\hline \multicolumn{1}{|c|}{ Types of bacteria } & $\begin{array}{c}\text { Conce } \\
\text { ntratio } \\
\mathrm{n}\end{array}$ & $\begin{array}{c}\text { Leaves } \\
\text { watery } \\
\text { extracts }\end{array}$ & $\begin{array}{c}\text { Leaves } \\
\text { alcoholic } \\
\text { extracts }\end{array}$ & $\begin{array}{c}\text { Seeds watery } \\
\text { extracts }\end{array}$ & $\begin{array}{c}\text { Seeds alcoholic } \\
\text { extracts }\end{array}$ \\
\hline E. coli & 0.01 & $7(44 \%)$ & $14(86 \%)$ & $7(44 \%)$ & $13.5(86.5 \%)$ \\
\hline & 0.02 & $6(43 \%)$ & $14(86 \%)$ & $7(43 \%)$ & $13(87 \%)$ \\
\hline & 0.1 & $50 \%$ & $100 \%$ & $45 \%$ & $100 \%$ \\
\hline & 0.2 & $50 \%$ & $100 \%$ & $46 \%$ & $100 \%$ \\
\hline & 0.5 & $60 \%$ & $100 \%$ & $50 \%$ & $100 \%$ \\
\hline Staphylococcusaureus & 0.01 & $8(46 \%)$ & $15(85 \%)$ & $8(46 \%)$ & $14(86 \%)$ \\
\hline & 0.02 & $11(66 \%)$ & $14(86 \%)$ & $10(65 \%)$ & $13(87 \%)$ \\
\hline & 0.1 & $68 \%$ & $100 \%$ & $60 \%$ & $100 \%$ \\
\hline & 0.2 & $72 \%$ & $100 \%$ & $60 \%$ & $100 \%$ \\
\hline Bacillus subtillus & 0.5 & $80 \%$ & $100 \%$ & $62 \%$ & $100 \%$ \\
\hline & 0.01 & $6(44 \%)$ & $12(88 \%)$ & $6(42 \%)$ & $11(89 \%)$ \\
\hline & 0.02 & $6(44 \%)$ & $11.5(88.5 \%)$ & $6(42 \%)$ & $13(90 \%)$ \\
\hline & 0.1 & $50 \%$ & $100 \%$ & $42 \%$ & $100 \%$ \\
\hline & 0.2 & $50 \%$ & $100 \%$ & $44 \%$ & $100 \%$ \\
\hline & 0.5 & $60 \%$ & $100 \%$ & $45 \%$ & $100 \%$ \\
\hline
\end{tabular}


The present study demonstrated that the activity of liver SOD was significantly enhanced by the presence of fenugreek seeds extracts. The mechanism of enhancement was observed by Joshi et al., (2014). They conclude that the depleted enzymatic and non-enzymatic anti-oxidants of diabetic rats were restored significantly with the treatment of fenugreek. Such effects may be mediated through the active phytoconstituents present in fenugreek, like 4-hydroxy isoleucine, diosgenin, orientin, quercetin. These active constituents can scavenge, or neutralize the free radicals or other ROS components (Baig et al., 2012; Punitha et al., 2005).

From this study we support the use of alcoholic fenugreek seeds and leaves extract was more active against the pathogenic bacteria than the watery fenugreek leaves extract and it may have a role in the treatment of some infectious diseases. This is in agreement with R. Chalghoumi et al., (2016) they conclude that antibacterial effect was demonstrated by the aqueous extract of fenugreek seeds; however, Iyer et al., (2004) they concluded that the organic extracts prepared with chloroform, acetone or methanol showed low to moderately high growth inhibitory effect $(8.33 \mathrm{~mm} \leq \mathrm{IZ} \leq 20$ $\mathrm{mm}$ ) when tested at a concentration equal to or above $5 \mathrm{mg} / \mathrm{ml}(24) 140 \mathrm{p}$.

In conclusion, from the present study, the following results can be concluded:

From the biochemical and physiological points of view, the model of $\mathrm{CCl} 4$ caused several changes in the level of the oxidative parameters, decreasing of GSH but fenugreek seed and leaves were succeeded in attenuating these changes when added to the $\mathrm{CCl} 4$ treated group and have shown hepatic protective effect by increasing the liver SOD levels

The model produced oxidative stress and rising in the levels of AST, ALT, ALP, direct bilirubin, but the current seeds and leaves lowered these levels.

Fenugreek seeds and leaves ameliorated inflammation caused by $\mathrm{CCl} 4$ treatment via decreasing of WBC and LYM count. Moreover, it decreased thrombogenic activity of $\mathrm{CCl} 4$ through decreasing of PLT count

From this study we support the use of alcoholic fenugreek seeds and leaves extract was more active against the pathogenic bacteria than the watery fenugreek leaves extract and it may have a role in the treatment of some infectious diseases.

\section{References}

Abboud, G. \& Kaplowitz, N. 2007. Druginduced liver injury. Drug Safety, 30, P. 277-294.

Albayati, F.H., Taiyeb, T.B., Abdulla, M.A. and Mahmud, Z.B. 2011. Antibacterial effects of oradexm gengidil and salviathymol-n mouth wash on dental biofilm bacteria. African. J. Microbial., 5(6): 636-642.

Amalraj, A., Balasubramanian, A., Edwin, E., Sheeja, E. 2005. Antimicrobial activity of petroleum ether and chloroform extracts of fenugreek seeds, Ind. J. Nat. Prod., 21(2): 35-36.

Amini, F.G., Rafieian-kopaei, M., Nematbakhsh, M., Baradaran, A. \& Nasri, H. 2012. Ameliorative effects of metformin on renal histologic and biochemical alterations of gentamicininduced renal toxicity in Wistar rats. $J$. Res. Med. Sci., 17.

Bahmani, M., Golshahi, H., Saki, K., Rafieian-kopaei, M., Delfan, B. \& Mohammadi, T. 2014a. Medicinal plants and secondary metabolites for diabetes mellitus control. Asian Pacific J. Trop. Dis., 4; S687-S692.

Bahmani, M., Shirzad, H., Majlesi, M., Shahinfard, N. \& Rafieian-kopaei, M. 
2014b. A review study on analgesic applications of Iranian medicinal plants. Asian Pacific J. Trop. Med., 7: P. S43S53.

Baig, M.A., Gawali, V.B., Patil, R.R. \& Naik, S.R. 2012. Protective effect of herbomineral formulation (Dolabi) on early diabetic nephropathy in streptozotocin-induced diabetic rats. $J$. Nat. Med., 66: 500-509.

Basu, T.K., Srichamroen, A., Ronald Ross, W. \& Victor, R. 2010. Health Benefits of Fenugreek (Trigonella foenumgraecum leguminosse. Bioactive foods in promoting health, $\mathrm{P} .425-435$.

Belguith-hadriche, O., Bouaziz, M., Jamoussi, K., El Feki, A., Sayadi, S. \& Makniayedi, F. 2010. Lipid-lowering and antioxidant effects of an ethyl acetate extract of fenugreek seeds in highcholesterol-fed rats. J. Agric. Food Chem., 58: P. 2116-2122.

Buege, J.A. \& Aust, S.D. 1978. Microsomal lipid peroxidation. Methods Enzymol., 52: 302-310.

Bukhari, S.B., Bhanger, M.I. \& Memon, S. 2008. Antioxidative Activity of Extracts from Fenugreek Seeds (Trigonella foenum graecum. Pak. J. Anal. Environ. Chem., 9: P.78-83

Chalghoumi, R., S. MabroukH. Abdoul and J.E. Line. 2016. Antibacteria 1Activityof Fenugreek Seeds (Trigonella foenumgraecum) Crude Extracts Against a Rabbit Escherichia coli Isolate

Chowdhury, P., Soulsby, M., Pasley, J., Mckay, D. \& Bansal, S. 2013. Effects of Dietary Soy Protein on Hematological and Tissue Oxidant/Anti-Oxidant Levels in Rats Exposed to Simulated Microgravity. J. Physical Chem. Biophysics.

Edziri, H., Mastouri, M., Mahjoub, M., Ammar, S., Mighri, Z., Gutmann, L. \& Aouni, M. 2011. Antiviral activity of leaves extracts of Marrubium alysson L.
J. Med. Plants Res., 5, P. 360-363.

Girish, C. \& Pradhan, S.C. 2008a. Drug development for liver diseases: focus on picroliv, ellagic acid and curcumin. Fundam. Clin. Pharmacol., 22: P.623632.

Girish, C. \& Pradhan, S.C. 2012. Hepatoprotective activities of picroliv, curcumin, and ellagic acid compared to silymarin on carbon-tetrachlorideinduced liver toxicity in mice. $J$. Pharmacol. Pharmacother., 3: P.14955.

Iyer, M., Belapurkar, H., Sherikar, O., Kasture, S.B. 2004. Anxiolytic activity of Trigonellafoenumgraecum seeds. $J$. Nat. Rem., 4(1): 61-65.

Joshi, D.V., Patil, R.R. \& Naik, S.R. 2014. Hydroalcohol extract of Trigonella foenum-graecum seed attenuates markers of inflammation and oxidative stress while improving exocrine function in diabetic rats. Pharm. Biol., P.1-11.

Kader, M., EL-Sayed, E., Kassem, S., Mohamed, H. \& Eldin, S. 2014. Protective and antioxidant effects of cynarascolymus leaves against carbon tetrachloride toxicity in rats. Res. J. Pharm. Bio Chem. Sci., 5: P.1373-80.

Kipkore, W., Wanjohi, B., Rono, H. \& Kigen, G. 2014. A study of the medicinal plants used by the Marakwet Community in Kenya. J. Ethnobiol. Ethnomed., 10: P.24.

Meera, R., Devi, P., Kameswari, B., Madhumitha, B. \& Merlin, N.J. 2009. Antioxidant and hepatoprotective activities of Ocimum basilicum Linn. and Trigonella foenum-graecum Linn. against $\mathrm{H} 2 \mathrm{O} 2$ and CCL4 induced hepatotoxicity in goat liver. Indian $J$. Exp. Biol., 47: P.584-90.

Moron, M.S., Depierre, J.W. \& Mannervik, B. 1979. Levels of glutathione, glutathione reductase and glutathione S-transferase 
activities in rat lung and liver. Biochimica et Biophysica Acta (BBA)General Subjects, 582, P.67-78.

Punitha, I., Rajendran, K., Shirwaikar, A. \& Shirwaikar, A. 2005. Alcoholic stem extract of Coscinium fenestratum regulates carbohydrate metabolism and improves antioxidant status in streptozotocin-nicotinamide induced diabetic rats. Evidence-Based Complementary and Alternative Med., 2, P.375-381.

Sewell, R.D. \& Rafieian-kopaei, M. 2014. The history and ups and downs of herbal medicines usage. J. Herb Med. Pharmacol., 3.

Sushma, N. \& Devasena, T. 2010. Aqueous extract of Trigonella foenum graecum (fenugreek) prevents cypermethrin- induced hepatotoxicity and nephrotoxicity. Hum. Exp. Toxicol., 29, P. 311-9.

Thirunavukkarasu, V., Anuradha, C. V. \& Viswanathan, P. 2003. Protective effect of fenugreek (Trigonella foenum graecum) seeds in experimental ethanol toxicity. Phytother. Res., 17: P.737-43.

Wang, X. \& Liu, Z. 2013. Prevention and treatment of viral respiratory infections by traditional Chinese herbs. Chinese Med. J., 127, P.1344-1350.

Webb, C. \& Twedt, D. 2008. Oxidative stress and liver disease. Vet. Clin. North America: Small Animal Practice, 38, P.125-135.

Yamamoto, Y.Y. 2000. Free radicals in chemistry, biology and medicine, OICA International (UK).

\section{How to cite this article:}

Firdaws A. AL-Mashhadani. 2017. Effect of Fenugreek Seed and Leaves on Some Hematological and Biochemical Parameters in CCl4-induced Liver Injury. Int.J.Curr.Microbiol.App.Sci. 6(4): 2328-2337. doi: https://doi.org/10.20546/ijcmas.2017.604.271 